Revista Cientifica do Instituto Agronómico, Campinas

\title{
SOBREVIVENCIA DE RHIZOBIUM JAPONICUM EM TURFA ESTERILIZADA COM RAIOS GAMA (1)
}

Eli Sidvey lopes $\left({ }^{2}\right)$, Antonio Roberto Giardini (2), Seção de Microbiologia do Solo, Instituto Agronómico, e LUIZ SANches (3), Pontifícia Universidade Católica de Campinas

No Brasil, o material usado como veículo nos inoculantes é um solo turfoso, com aproximadamente $10-12 \%$ de carbono. Resultados práticos têm mostrado que esse material se presta satisfatoriamente e ensaios conduzidos para comprovar a qualidade dos inoculantes confirmam que o material é adequado $\left({ }^{4.5}\right)$. A produção brasileira de inoculantes utilizando esse tipo de material chega a ser de seis milhões de pacotinhos/ano.

$\mathrm{Na}$ fabricação de inoculantes, três fatores devem ser considerados fundamentais para obter um produto de boa qualidade: a utilização de bactérias pré-selecionadas, a multiplicação dessas bactérias em condições assépticas e o preparo adequado da turfa.

No Brasil, a turfa normalmente não é esterilizada para a fabricação de inoculante. Para o caso das leguminosas forrageiras, há informaçōes de que alguns produtores de inoculantes fazem a esterilização por autoclavagem. Outro processo de esterilização que tem apresentado bons resultados é através da irradiação gama, conforme trabalhos de ROUGHLEY \& VINCENT $\left(^{6}\right)$ e CERVENANS-

\footnotetext{
(1) Trabalho apresentado na $9 .^{\text {a }}$ Reuniāo Latino-americana sobre Rhizobium, 1978, México. Projeto FAPESP 72/1464. Recebido para publicação a 13 de novembro de 1979.

(2) Com bolsa de suplementação do CNPq.

(9) Físico Nuclear - IBRAS-CBO e Professor da Pontifícia Universidade Católica de Campinas.

(4) LOPES, E. S. \& GIARDINI, A. R. Sobrevivência de Rhizobium phaseoli em turfa esterilizada. Bragantia, Campinas, 36:XXXIX-XIII, 1977. Nota, 10.

(5) - E LAUN, R. Ensaio comparativo da qualidade de diversos inoculantes comerciais. (Náo publicado)

(') ROUGHLEY, R. J. \& VINCENT, J. M. Growth and survival of Rhizobium spp. in peat cultura. Journal Appled Bacteriology, 30(2):363-376, 1967.
} 
KY $\left({ }^{7}\right)$. Esse processo é vantajoso, pois a turfa pode ser esterilizada no próprio pacote e a adição do caldo inoculante, feita através de injeção em condições de assepsia. Além disso, o tempo para multiplicação das bactérias durante o processamento industrial pode ser abreviado, diminuindo as chances de contaminação, já que ocorre multiplicação satisfatória das bactérias do caldo inoculado no interior dos pacotinhos.

Esse trabalho foi conduzido com o objetivo de verificar a sobrevivência de Rhizobium japonicum em turfa esterilizada com raios gama e por calor.

Material e métodos: A turfa empregada havia sido preparada e empacotada para uso em inoculantes comerciais ( $\mathrm{pH}$ corrigido, moída e seca em fornos rotativos a cerca de $80^{\circ} \mathrm{C}$ ), sendo da mesma procedência $\left(^{8}\right)$ e semelhante à usada anteriormente por LOPES \& GIARDINI $\left({ }^{4}\right)$.

Os inoculantes em teste foram preparados por injeção de caldo de cultivo nos sacos plásticos, previamente selados, com $130 \mathrm{~g}$ de turfa autoclavada, irradiada, ou não esterilizada, conforme o tratamento. $\mathrm{O}$ caldo injetado, da estirpe SMS-313 (= RS/SEMIA 566), proporcio- nou aos diversos inoculantes uma população inicial de $2,3 \times 10^{8}$ bactérias viáveis/grama de turfa úmida ( $38 \%$ de umidade). Após a inoculação, os pacotinhos foram devidamente selados no ponto da injeção e armazenados à temperatura ambiente, no laboratório.

Foram feitas três repetições (três pacotinhos) de cada um dos seguintes tratamentos:

1) Sem esterilização da turfa.

2) Esterilização em autoclave (turfa autoclavada e depois embalada na indústria).

3) Esterilização com raios gama, 2,25 megaran-

4) $r$

gama

A .u da turfa foi efetua. sera IBRAS-CBO, Indústrias Cirúrgicas e ópticas, Campinas, com um irradiador de fluxo contínuo.

Antes de inocular o caldo nos pacotinhos, fez-se uma contagem de microrganismos na turfa não esterilizada. Utilizou-se meio de peptona para contagem geral de microrganismos $\left({ }^{9}\right)$, meio diferencial para fungos $\left({ }^{10}\right)$ e actinomicetos (11), bem como testes para comprovar a eficiência de esterilização na turfa autoclavada ou irradiada. Para verificação de

(i) CERVENANSKY, C. Survivar of Rhizobium in different peat cultures. In: INTERNATIONAL LATIN AMERICAN SYMPOSIUM, 15, Brasilia, 1977. Limitions and potentials for biological nitrogen fixation in the tropics. Edited by $J$. Dobereiner et ali1. New York, Plenum Press, 1978. p.358. (Basic life sciences, 10)

${ }^{8}$ TURFAL, Ind. Prod. Quím. Agron. Ltda., Sete Barras (PR).

( ${ }^{(2)}$ STEVENSON, I. L. \& ROUAT, J. W. Qualitative studies of soil micro-organisms Canadian Journal of Botany, 31:438-477, 1953.

(10) MARTIN, J. P. Use of acid, rose bengal and streptomycin in the plate method for estimating soil fungi. Soil Science, 69:215-233, 1950.

(i1) KENKNIGHT, G. \& MUNCIE. J. H. Isolation of phytopathogenic actinomycetes. Phytopathology, 29:1000-1001, 1939. 
desenvolvimento e sobrevivência do Rhizobium nos inoculantes, foram feitas contagens aos 19-20, $28-32,60$ e 188 dias após a adição do caldo, em cada repetição, pela técnica da diluição em placas com meio manitol-levedura ${ }^{(12)}$. Usou-se $1 \mathrm{~g}$ de inoculante para cada uma das séries de diluições e foram plaqueadas alíquotas de $0,1 \mathrm{ml}$ das diluiçōes $10^{-\mathrm{s}}$ a $10^{-\tau}$, com cinco repetições, sendo as placas incubadas a $28^{\circ} \mathrm{C}$. Periodicamente, fez-se a determinação de umidade de algumas amostras.

Resultados e discussão: Os resultados de contagem prévia de microrganismos na turfa, em meio de peptona, revelaram cerca de $1,7 \times 10^{6}$ microrganismos/grama, com predominância de bactérias nas placas de contagens. Em meio diferencial para fungos, constatou-se, entretanto, um número ele-

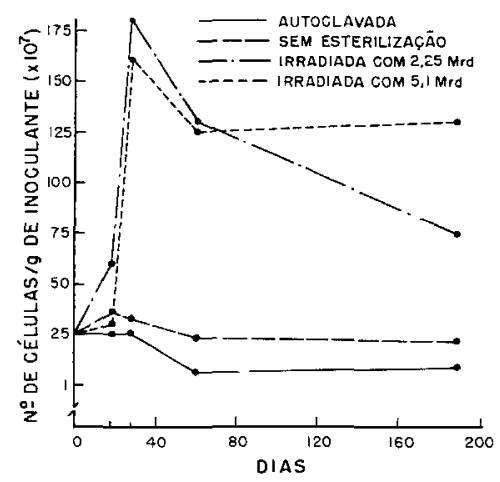

Figura 1. - Resultados das contagens de Rhizobium em diferentes épocas, obșervadas em inoculantes preparados com turfa não esterilizada, autoclavada, ou irradiada com dosagens de raios gama, e armazenada por 188 dias. vado de colônias, equivalentes a $1,6 \times 10^{6}$ propágulos/grama.

A turfa autoclavada e posteriormente embalada estava contaminada e continha grande número de colônias semelhantes a algumas estirpes de Rhizobium japonicum (circulares, leitosas, convexas, de crescimento lento). A recontaminação da turfa autoclavada deve ter ocorrido durante o processo de empacotamento. As irradiações com 2,25 ou com 5,10 megarads foram igualmente eficientes na desinfecção da turfa, não se observando crescimento de microrganismos em placas com meio de peptona, inoculado com $0,1 \mathrm{~g}$ de turfa/placa, ou com inoculação maciça em meio líquido anaeróbico (Nutrient Broth-Difco) e aeróbico (Eugon Broth-Difco).

Durante o período de armazenamento e por ocasião da última contagem, a umidade da turfa estava em torno de $37 \%$.

A figura 1 mostra os resultados das contagens efetuadas nas diferentes épocas de amostragem, para os quatro tratamentos.

Pela contagem feita aos 18-20 dias, pode-se verificar que houve uma multiplicação de células nesse período nos tratamentos sem esterilização, ou esterilizados com raios gama (2,25 e 5,10 Mrad), o que não parece ter ocorrido com a turfa autoclavada, que manteve praticamente a mesma população inicial. A multiplicação de células continuou nos dois tratamentos com turfa irradiada, que apresen-

(12) VINCENT, J. M. A manual for the practical study of the root-nodule bacteria. Oxford. Blackwell, 1970. 150p. (IBP Handbook, 15) 
taram um número de Rhizobium cerca de cinco vezes maior que os demais tratamentos na contagem do $32^{\circ}$ dia. $\mathrm{Na}$ contagem efetuada aos 60 dias, verificou-se um decréscimo na população de $R h i$ zobium em todos os tratamentos, na proporçāo de $16,7 \%\left(30 \times 10^{7}\right.$ células/grama) no tratamento irradiado com 2,25 megarads, $24,2 \%\left(40 \times 10^{7}\right.$ células/grama) no tratamento irradiado com 5,10 megarads, $42,8 \%$ (15 $\times 10^{7}$ células/grama) no tratamento sem esterilização e $80 \%\left(\begin{array}{llll}20 & \text { x } & 10^{7}\end{array}\right.$ células/grama) no tratamento autoclavado.

Aos 188 dias a população permaneceu inalterada em relação à população encontrada na contagem feita aos 60 dias, exceto para o tratamento irradiado com 2,25 megarads, que teve uma queda de $52,7 \%\left(78 \times 10^{7}\right.$ células/ grama) em relação à última contagem. Até o $188^{\circ}$ dia a população no tratamento irradiado com $\mathbf{5 , 1 0}$ megarads era treze vezes maior que o tratamento autoclavado, sete vezes maior que o sem esterilização e duas vezes maior que o irradiado com 2,25 megarads.

E difícil explicar o efeito diferente das duas dosagens de radiação gama na evolução do número de rizóbios. Ela pode ser atribuída, entretanto, à alteração qualitativa, nos constituintes da turfa, particularmente nos de natureza orgânica, de acordo com a dosagem.

É interessante observar que na turfa não esterilizada e na au- toclavada não houve multiplicações dos rizóbios após a mistura, como nos tratamentos irradiados. Há duas possibilidades, pelo menos, para explicar a não multiplicação nas turfas não esterilizada e autoclavada: a liberação $\mathrm{e} / \mathrm{ou}$ formação de produtos químicos devido à autoclavagem, e antagonismos com microrganismos existentes na turfa.

Os resultados deste trabalho confirmam os de ROUGHLEY \& VINCENT $\left({ }^{\circ}\right)$ e de CERVENANSKY ( $\left.{ }^{7}\right)$, que verificaram que a esterilização da turfa através da irradiação gama foi superior ao processo de autoclavagem.

Fizeram-se ainda contagens adicionais de células aos 220 dias no tratamento sem esterilização, aos 240 no tratamento com turfa autoclavada, aos 260 no tratamento com turfa irradiada com 2,25 Mrad e aos 290 na turfa irradiada com 5,10 Mrad. Os resultados dessas contagens mostraram que, no tratamento com 5,10 Mrad, a população se manteve alta, decresceu no tratamento com 2,25 $\mathrm{Mrad}$, e manteve-se baixa nos tratamentos autoclavado e não esterilizado, confirmando as tendências já observadas para a contagem efetuada aos 188 dias após a inoculação.

E necessário salientar que, apesar dos melhores resultados terem sido obtidos com a turfa irradiada, os inoculantes preparados com turfa não esterilizada ainda mantêm um pouco mais de $10^{7}$ rizóbios/grama, que é o minimo exigido pela legislação brasileira. 


\section{SURVIVAL OF RHIZOBIUM JAPONICUM IN IRRADIATED PEAT}

\section{SUMMARY}

Peat like substrate, ready for use by inoculant industry was gama irradiated at 2.25 and 5.10 megarads in sealed plastic bags. Non sterilized, and autoclaved peat were also packed and sealed. Broth of strain SMS-313 (RS/SEMIA 566) was injected to give $33 \%$ umidity into each peat treatment and $2.3 \times 10^{3} \mathrm{rhizobia} / \mathrm{g}$ of wet inoculant.

The bags were mantained at room temperature, and six samples of each treatment were collected at different intervals, during 290 days, to count the number of bacteria. In both dosis of irradiation there was a sharp increase in rhizobia. Maximum numbers in the period were reached in between 32 and 60 days. At the second sampling ( 32 days) population in both irradiated treatment had circa $1.8 \times 10^{\circ}$ rhizobia/g wet peat. In the non sterilized and autoclaved peat treatments the maximum numbers of rhizobia were much lower $\left(3.0 \times 10^{8}\right)$.

A gradual decrease in number of rhizobia, in the irradiated treatment was observed, but a higher number of rhizobia was mantained throughout the experiment, as compared to the non sterilized, or autoclaved peat. 